\title{
Evaluation of Later Morphologic Alterations in Renal Artery Wall and Renal Nerves in Response to Catheter-Based Renal Denervation in Sheep: Comparison of the Single-Point and Multiple-Point Ablation Catheters
}

\author{
M. TÁBORSKÝ ${ }^{1}$, D. RICHTER ${ }^{1}$, Z. TONAR $^{2}$, T. KUBÍKOVÁ ${ }^{2}$, A. HERMAN $^{3}$, \\ J. PEREGRIN ${ }^{3}$, Z. HUSKOVÁ ${ }^{3}$, L. KOPKAN ${ }^{3}$ \\ ${ }^{1}$ Department of Internal Medicine I, Cardiology, University Hospital Olomouc and Palacký \\ University, Olomouc, Czech Republic, ${ }^{2}$ Department of Histology and Embryology and Biomedical \\ Center, Faculty of Medicine in Pilsen, Charles University in Prague, Pilsen, Czech Republic, \\ ${ }^{3}$ Center for Experimental Medicine, Institute for Clinical and Experimental Medicine, Prague, \\ Czech Republic
}

Received January 24, 2018

Accepted July 10, 2018

On-line September 11, 2018

\section{Summary}

This study evaluated the subacute morphologic alterations in renal artery wall and renal nerves in response to catheter-based renal denervation (RDN) in sheep and also compared the efficiency of single-point and multiple-point ablation catheters. Effect of each ablation catheter approved for the clinical use (Symplicity Flex ${ }^{\mathrm{TM}}$, Medtronic, Inc., or EnligHTN ${ }^{\mathrm{TM}}$, St. Jude Medical, INC.) was compared to intact contralateral renal artery in 12 sheep by histopathology and immunohistochemistry evaluation after a 10-day period post-RDN procedure. The safety was verified by extensive evaluation of kidney morphology. Vascular wall lesions and nerve injuries were more pronounced in those animals treated with multi-point EnligHTN catheter when compared with animals treated with single-point Symplicity Flex catheter. However, neither RDN procedure led to complete renal nerve ablation. Both systems, tested in the present study, provided only incomplete renal nerve ablation in sheep. Moreover, no appreciable progression of the nerve disintegration in subacute phase post-RDN procedure was observed. This study further supports the notion that the effectiveness remains fully dependent on anatomical inter-individual variability of the sympathetic nerve plexus accompanying the renal artery. Therefore, new systems providing deeper penetrance to targeted perivascular structure would be more efficient.

\author{
Key words \\ Renal denervation • Experimental approach • Histology • \\ Resistant hypertension
}

\section{Corresponding author}

M. Táborský, Department of Internal Medicine I, Cardiology, University Hospital Olomouc and Palacký University, I. P. Pavlova 6, 77520 Olomouc, Czech Republic. E-mail: milos.taborsky@seznam.cz

\section{Introduction}

Despite several controversies in the clinical trials (Mahfoud et al. 2013, Bhatt et al. 2014, Bakris et al. 2015) the ablation of renal sympathetic nerves by radiofrequency ablation catheter $(\mathrm{RDN})$ is still considered to be a potential approach for the resistant hypertension treatment (Kandzari et al. 2016, Townsend et al. 2017). This procedure remains a dynamically developing approach in clinical cardiology aiming to improve its safety and efficacy. However, this method is challenged by many technical and procedural issues. One of its major limitations lies in monitoring the success of the procedure. There are no clear tests determining whether the denervation procedure has been wholly or partially effective or ineffective (Mahfoud et al. 2013). Therefore, 
experimental approaches are still important to reveal direct morphologic alterations in the renal artery and renal nerves in response to catheter-based RDN (Rippy et al. 2011, Steigerwald et al. 2012, Cohen-Mazor et al. 2014, Sakakura et al. 2015, Táborský et al. 2017).

In our previous study (Táborský et al. 2017), we elucidated single-point and multi-point RDN-induced early changes in sheep as vascular and nerve injury score along the renal artery $48 \mathrm{~h}$ post procedure. Although the multi-point system displayed significantly higher efficiency in comparison with single-point device, we determined that neither of the RDN systems achieved complete damage of the targeted renal nerve plexus or significantly reduced the level of catecholamines in the post-RDN kidney. However, there is lacking evidence whether further progression of tissue damage may occur as consecutive disruption of distal nerve structures from the successful denervation spots located proximally or as a consequence of healing processes postRDNprocedure (Rippy et al. 2011, Steigerwald et al. 2012, Mahfoud et al. 2017). Furthermore, any direct comparison of different ablation system has not yet been performed.

Therefore, the main goal of this study was to assess the later (subacute) morphologic alterations in renal artery wall and renal nerves in response to catheterbased renal denervation in sheep. The possible hemodynamic alteration of the renal artery was verified by angiography at the end of RDN procedure and also after a 10-day period to verify the safety of the methods. Histopathology and immunohistochemistry evaluation was also performed to describe present alterations to the affected renal artery and accompanying renal nerve plexus in comparison with the contralateral renal artery. We focused on the description of radio-frequency ablation induced subacute intravascular, vascular and peri-vascular changes by single-point and multiple-point ablation catheters as we reported previously (Táborský et al. 2017).

\section{Methods}

The study performed in sheep (total $\mathrm{n}=12$; body weight $31-45 \mathrm{~kg}$ ) was approved by the Institute for Clinical and Experimental Medicine Animal Care and Use Committee in accordance with the regulations accepted in the Czech Republic and guidelines from Directive 2010/63/EU of the European Parliament.

\section{Renal artery angiography and $R D N$ procedure}

To follow our previous study (Táborský et al.
2017), the animals were randomly assigned into two mixed sex groups ( $\mathrm{n}=6$ in each group). All intervention procedures were designed as described recently (Táborský et al. 2017): anesthesia was induced with combination of propofol $(10 \mathrm{mg} / \mathrm{kg}$; Fresenius Kabi, Bad Homburg, Germany) and fentanyl $(3 \mathrm{mg} / \mathrm{kg}$; Torrex, Chiesi, Wien, Austria) given intravenously. After endotracheal intubation, anesthesia was maintained with $0.5 \%$ to $2.0 \%$ isoflurane (Isofluran Rhodia, Nicholas Piramar, Mumbai, India) $-\mathrm{O}_{2}$ /air mixture. During whole surgical procedures, $\mathrm{pO}_{2} / \mathrm{pCO}_{2}$ and $\mathrm{pH}$ were monitored (Carescape B850, GE Medical Systems, Freiburg, Germany). The access point for the catheterization was performed via right femoral artery to introduce a sheath into the exposed artery and heparinized (3,000 IU). Blood pressure was recorded for $5 \mathrm{~min}$ via a pressure module (Carescape B850) and blood sample was taken. Then a pigtail catheter was inserted through the sheath into renal arteries area. Abdominal aorta angiography was performed using a standard contrast agent (Telebrix 35, Guerbet BP, Roissy CdG Cedex, France) injection to assess renal arteries origin anatomy before applying the RDN procedure. The guiding catheter was inserted into right renal artery and appropriate ablation catheter approved for clinical use (Symplicity Flex ${ }^{\mathrm{TM}}$, Medtronic, Inc., Santa Rosa, CA, USA or EnligHTN ${ }^{\mathrm{TM}}$ Basket, St. Jude Medical, Inc., Saint Paul, MN, USA), connected to a generator and RDN procedure of 12-13 successful cycles was performed. After removing the ablation catheter, control angiography of both arteries was repeated. The procedure was finalized by withdrawal of the catheter, wire and sheath, and closing of the femoral wound. Sheep were monitored till full recovery from anesthesia, an analgesic butorphanol $0.2-0.4 \mathrm{mg} / \mathrm{kg}$ s.c. (Torbugesic, Zoetis Manufacturing and Research Spain S.L., Vall de Bianya, Spain) was administered.

10 days post-RDN the animals were anesthetized and prepared by the same procedure as described above for the second angiography of both renal arteries via left femoral artery (Táborský et al. 2017). After that, the animals were euthanized by an anesthetics overdose (thiopental, VUAB Brno, Czech Republic) with $\mathrm{KCl}$. Then their abdomen was opened to check the kidneys macroscopically, the whole block (the abdominal aorta with attached renal arteries and kidneys) was taken out and immediately flushed by $10 \%$ buffered formalin and excised for histological examination.

\section{Histological processing}

The extensive sampling scheme was identical for the organs subjected to RDN and for the intact 
contralateral organs from each animal studied. The tissue blocks were harvested as described previously (Táborský et al. 2017). Complete renal arteries were cut into a series of $3 \mathrm{~mm}$ long vascular segments. These covered the entire length of the renal artery from its origin from abdominal aorta up to its branching. According to individual lengths, between 8 and 9 samples were obtained from each renal artery and those were processed in series of transversal sections, oriented in histological cassettes, fixed with $10 \%$ buffered formalin solution, dehydrated in alcohol, embedded in paraffin and cut into $4 \mu \mathrm{m}$ thick sections. Part of the middle region of kidney from the surface of the kidney cortex to the innermost parts of medulla and connective tissue within the renal sinus was also collected to evaluate the impact of RDN on morphology of the kidney. Seven staining methods, including four immunohistochemical methods, were applied and combined to reveal the most important microscopic features of the vascular wall, sympathetic peripheral nerves, kidney and suprarenal gland morphology. The staining methods, the primary antibodies used, the purpose and biological interpretation of each method are summarized in Table 1.

Table 1. Histological staining methods.

\begin{tabular}{ll}
\hline Staining method & Purpose and interpretation \\
\hline Hematoxylin-eosin & $\begin{array}{l}\text { Overall morphology of all organs, thickness of the } \\
\text { arterial wall, inflammatory infiltration. }\end{array}$ \\
\hline Verhoeff's hematoxylin and green trichrome, Mallory & $\begin{array}{l}\text { Overall morphology of all organs; arterial wall } \\
\text { thickness and proportions of the tunica intima, media, } \\
\text { trichrome }\end{array}$ \\
$\begin{array}{l}\text { and adventitia layers. Contrast staining of vascular } \\
\text { smooth muscle, elastin, and collagen in the vascular } \\
\text { wall. Epineurium, perineurium, and endoneurium } \\
\text { connective tissue in the peripheral nerves. }\end{array}$
\end{tabular}

Orcein (Tanzer's orcein, Bowley Biochemical Inc., Elastic membranes in the renal arteries. Danvers, MA, USA)

\begin{abstract}
Immunohistochemical detection of actin microfilament using the Monoclonal Mouse Anti-Human Smooth Muscle Actin Antibody, Clone 1A4 (Dako), dilution 1:100, pretreatment Target Retrieval Solution (DakoCytomation S1700), $\mathrm{pH} 9.0,96{ }^{\circ} \mathrm{C}, 20 \mathrm{~min}$
\end{abstract}

Immunohistochemical detection of neurofilament protein using the Monoclonal Mouse Anti-Human Neurofilament Protein Antibody, Clone 2F11 (DakoCytomation), dilution 1:75, pretreatment Target Retrieval Solution (DakoCytomation S1700), pH 6.0, $96^{\circ} \mathrm{C}, 20 \mathrm{~min}$

Immunohistochemical detection of tyrosine hydroxylase using the Polyclonal Rabbit Anti-Tyrosine Hydroxylase (DakoCytomation), dilution 1:1,000, pretreatment Target Retrieval Solution (DakoCytomation S1700), $\mathrm{pH} 9.0,96^{\circ} \mathrm{C}, 20 \mathrm{~min}$

Immunohistochemical detection of von Willebrand factor using the Polyclonal Rabbit Anti-Human Von Willebrand Factor (DakoCytomation), solution 1:200, pretreatment $10 \mathrm{~min}$ in chilled acetone and Proteinase K (DakoCytomation)
Specific detection of contractile phenotype of vascular smooth muscle in the wall of the renal arteries.

Specific detection of intermediate filament of neuronal processes in the peripheral nerve fibres.

Specific detection of the tyrosine hydroxylase enzyme typical for adrenergic sympathetic neurons.

Specific detection of endothelial cells, especially in the microvessels of the vasa vasorum supplying the renal arteries and in the vasa nervorum supplying the peripheral nerves. 
Table 2. Semiquantitative scale for assessing the injury of renal artery and adjacent peripheral nerves using transverse histological sections. Points (1-4) were allocated per each arterial quadrant containing the injury of the artery or nerves in the segment under study.

\begin{tabular}{ll}
\hline \multicolumn{1}{c}{ Injury assessment of the RDN-intervened renal artery } \\
\hline Points per each arterial segment & Histological injury found in renal artery \\
\hline 0 & no histological signs of injury \\
$1-4$ & eccentric focal damage and weakening of the wall \\
$1-4$ & collagen denaturation \\
$1-4$ & damaged elastic membranes \\
$1-4$ & loss of immunopositivity for alpha-smooth muscle actin \\
$1-4$ & damage to the vasa vasorum \\
1 & presence of intraluminal thrombus \\
\hline Points per each nerve segment & Histological injury found in nerves surrounding the renal artery \\
\hline 0 & no histological signs of injury \\
$1-4$ & hyperemia of nerve \\
$1-4$ & destructive fragmentation or complete loss of nuclei of Schwann cells \\
$1-4$ & damage to the inner nerve structure: loss of neurilemma and structure of the \\
& endoneurial connective tissue \\
$1-4$ & loss of immunopositivity for neurofilament protein \\
$1-4$ & loss of immunopositivity for tyrosine hydroxylase
\end{tabular}

Histological evaluation of RDN-induced alterations in the intervened renal arteries, renal nerves, kidneys

During evaluation, the histological samples from experimental groups were labelled with number codes and the histologist (Z. T.) was blinded from the identity of the treatment during the course of the experiment. The scoring system reflected severity (or grade) of the damage done to the artery wall and adjacent nerves, and the relative extent of these changes after 10 days postRDN procedure. The classification and scoring are given in Table 2. These values were calculated for each studied sample and presented as mean vascular/nerve injury score per segment - arithmetic mean value of the score results per one segment. This was calculated by dividing the sum of the vascular injury score, or the sum of the nerve injury score, respectively, by the number of arterial segments in any given animal and organ (Táborský et al. 2017).

\section{Plasma analysis}

The enzymatic method of measurement by spectrophotometry (Abott Architect c16000, Abbott Laboratories, Ltd., Prague, Czech Republic) was used to assess plasma creatinine and urea prior RDN and also 10 days later.

\section{Statistical analysis}

The non-parametric Wilcoxon matched pairs test was used to compare the results found in RDN intervened and intact organs of the same animal. The Mann-Whitney $\mathrm{U}$ test was used to assess the differences between the results of intervention using two different types of catheters. The correlation between the parameters calculated from the scoring systems was evaluated using the Spearman correlation coefficient. These tests were used as available in the Statistica Base 11 package (StatSoft, Inc., Tulsa, OK, USA).

\section{Results}

In the present study, both procedures using single-point and multiple-point ablation catheters did not cause any serious hemodynamic alteration of the intervened kidney confirmed by post-RDN angiography. No evidence of renal artery stenosis, thrombosis, dissection, perforation or spasm was apparent based on angiography both immediately post-procedure and after the 10-day period, indicating the safety of these methods.

In addition, both RDN systems did not markedly affect the mean arterial pressure (Symplicity $113 \pm 4$ to $109 \pm 3 \mathrm{~mm} \mathrm{Hg}$ and EnligHTN $116 \pm 5$ to $112 \pm 3 \mathrm{~mm} \mathrm{Hg}$ ), plasma creatinine (Symplicity $55.1 \pm 3.2$ to $63.3 \pm 3.8 \mu \mathrm{mol} / \mathrm{l}$ and EnligHTN $55.7 \pm 3.6$ to $60.4 \pm 4.1 \mu \mathrm{mol} / \mathrm{l}$ ), and urea (Symplicity $4.02 \pm 0.37$ to $4.35 \pm 0.45 \mathrm{mmol} / \mathrm{l}$ and EnligHTN $3.57 \pm 0.51$ to $4.18 \pm 0.46 \mu \mathrm{mol} / \mathrm{l})$ after 10 days. 

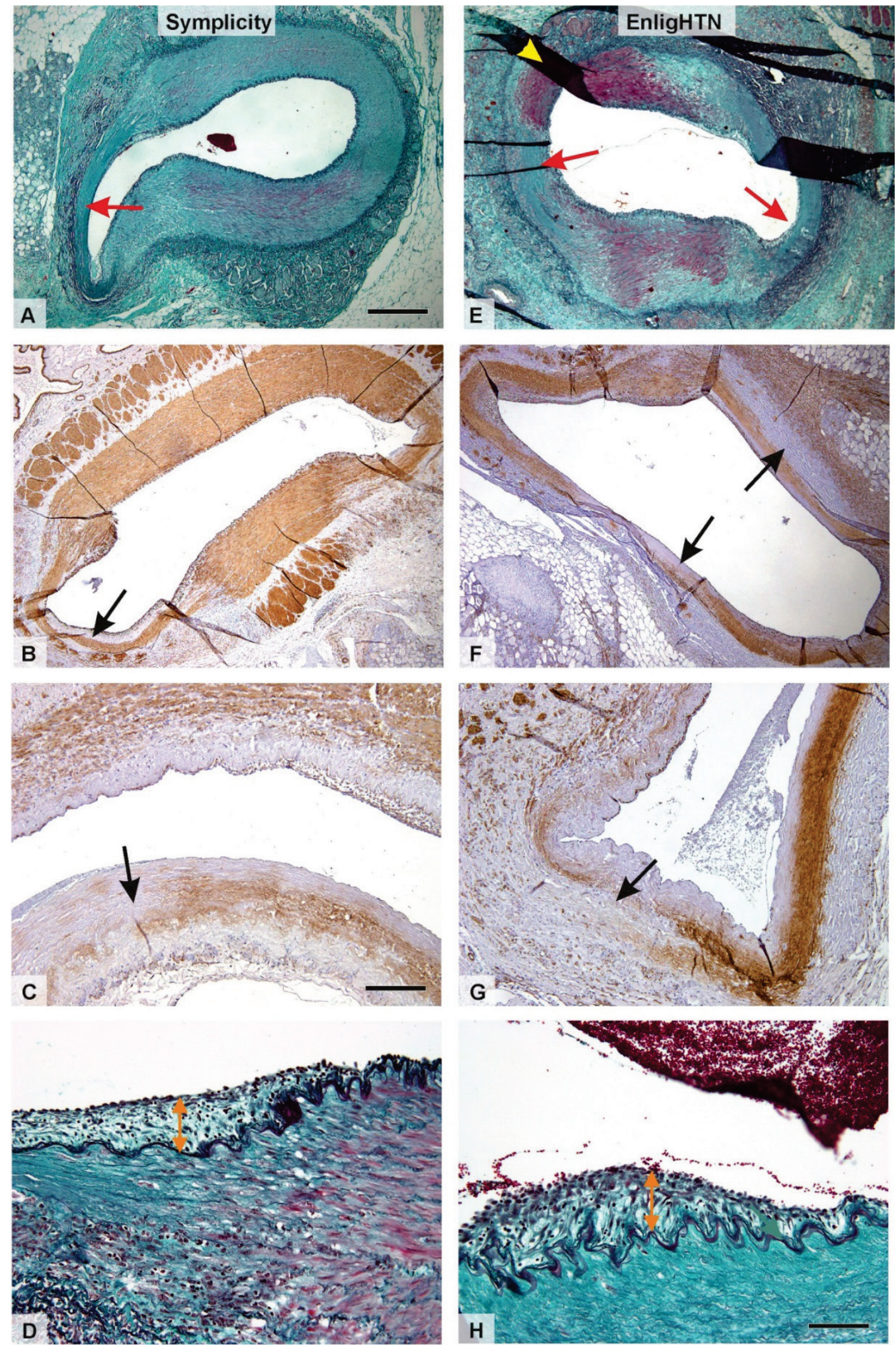

Fig. 1. Representative histological findings of arterial injury in both groups of animals after 10 days post-RDN intervention using the Symplicity Flex catheter (left) and EnligHTN catheter (right). Eccentric focal damage and weakening of the wall (A, E; red arrows). Damaged elastic membranes and loss of immunopositivity for alpha-smooth muscle actin within the tunica media layer (B, C, F, G; black arrows). Eccentric thickening of neointima adluminal to the lamina elastica interna was occasionally found (D, H; orange arrows). In the renal arteries treated with the Symplicity catheter, the lesions of vascular wall were less extensive, often affecting only one quadrant of the histological section. In the renal arteries treated with the EnligHTN catheter, the impact was observed in more quadrants. Verhoeff's hematoxylin and green trichrome staining $(\mathbf{A}, \mathbf{D}, \mathbf{E}, \mathbf{H})$, immunohistochemical detection of alpha-smooth muscle actin in vascular smooth muscle (B, C, F, G; dark brown positivity). Scale bar $500 \mu \mathrm{m}$ (A-B, E-F), $200 \mu \mathrm{m}(\mathrm{C}, \mathrm{G})$ and $100 \mu \mathrm{m}(\mathrm{D}, \mathrm{H})$. 

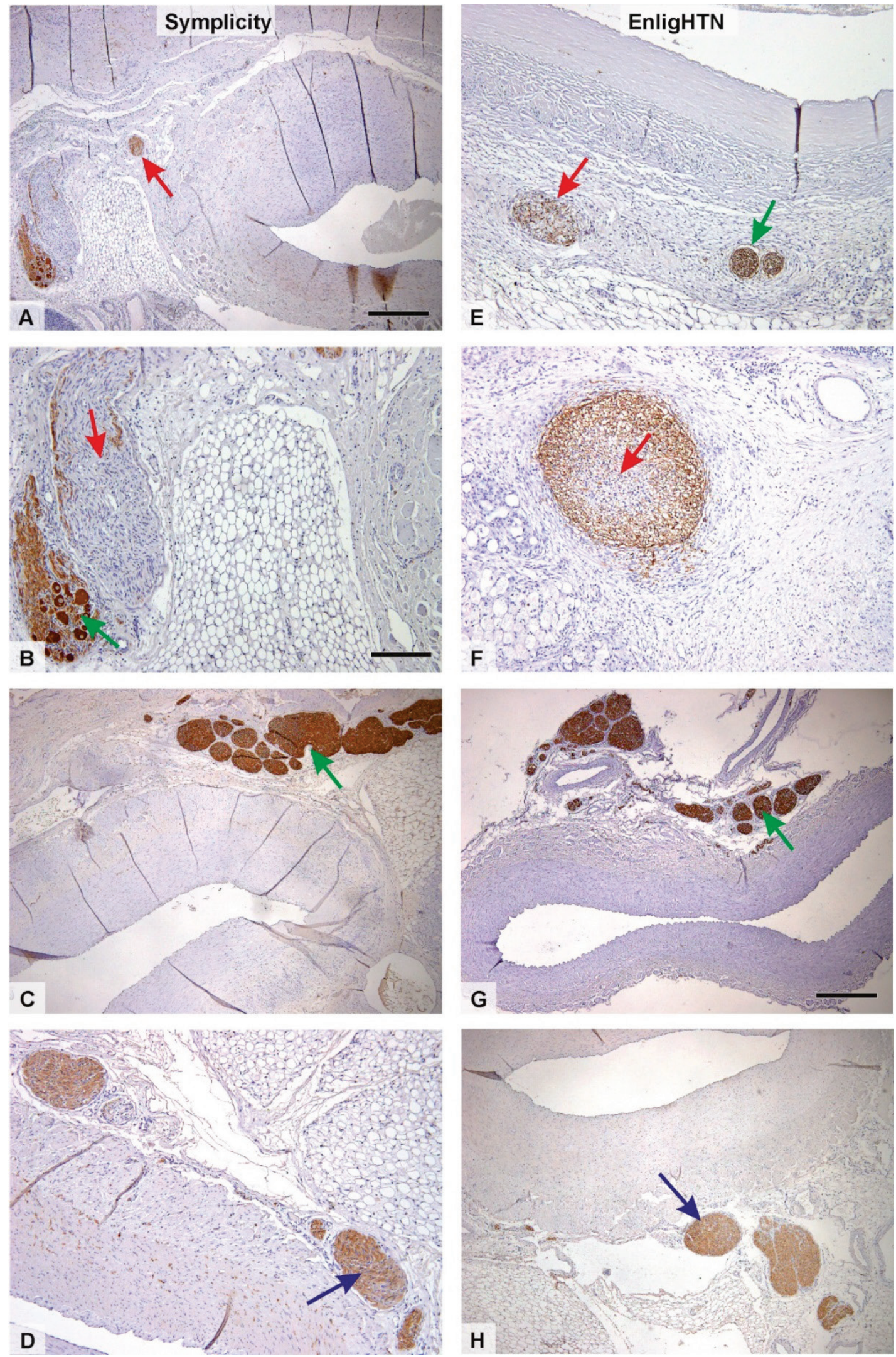

Fig. 2. Representative histological findings of damaged nerves in both groups of animals after 10 days post-RDN intervention using the Symplicity Flex catheter (left) and EnligHTN catheter (right). In many sections, damaged nerves (red arrows) showing focal loss of immunopositivity for neurofilament protein (A-C, E-G) and tyrosine hydroxylase (C, G) were found. Also healthy and morphologically and immunohistochemically normal nerves were found (B, C, E, G; green arrows) adjacent to the renal artery. In more distal arterial segments close to the kidney, well preserved nerve bundles were regularly found in both study groups (D, H; blue arrows). Immunohistochemical detection of neurofilament protein (A-C, E-G; dark brown positivity), immunohistochemical detection of tyrosine hydroxylase (C-G, dark brown positivity). Scale bar $500 \mu \mathrm{m}(\mathrm{A}, \mathrm{C}-\mathrm{E}, \mathrm{G}-\mathrm{H}), 200 \mu \mathrm{m}(\mathrm{B}, \mathrm{F})$. 
Vascular and nerve injury status with and without RDN intervention

The evaluation confirmed that the collateral renal artery and kidney without RDN intervention remained intact. Both groups of animals treated with the Medtronic Symplicity Flex catheter or the EnligHTN multi-point catheter exhibit some degree of vascular (Fig. 1) and nerve injury (Fig. 2) induced by RDN procedure. Representative histological findings showing the changes in the renal artery wall after RDN intervention are depicted in Figure 1. Typical alteration was weakening of the wall and collagen denaturation with smooth muscle loss. Intraluminal thrombus formations were not found after 10 days. In the renal arteries treated with the Medtronic Symplicity catheter, the lesions of the vascular wall were less extensive and usually presented in just one quadrant of the vascular section (Figs 1A-D). In arteries treated with the EnligHTN catheter, the vascular lesions were more extensive, often affecting multiple quadrants in cross sections of several segments (Figs 1E-H). In both groups, we observed focal eccentric formation of neointima, consisting of proliferation of subendothelial connective tissue bounded by the internal elastic lamina. These foci were found to be associated with both intraluminal thrombi and in vascular segments without thrombi. The lesions did not contain smooth muscle cells and their thickness did not exceed $150 \mu \mathrm{m}$.

Typical findings in nerves accompanying the renal arteries were a partial damage of the nerve bundles that were located close to the vascular lesions, showing focal loss of immunopositivity for neurofilament protein or tyrosine hydroxylase (Figs 2A, 2B, 2E and 2F) particularly observed in the proximal segments of the renal artery. Morphologically normal unaltered nerves were found, often in the direction opposite to the damaged arterial quadrant or in the distal segments of the renal artery (Figs 2C, 2D, 2G and 2H). All types of nerve injury were also more pronounced in the animals treated with EnligHTN catheter when compared with animals treated with Medronic Symplicity catheter. Comparison of both RDN systems assessed by the scoring system (Táborský et al. 2017) resulted in significantly greater injury to the renal artery represented as a mean vascular injury per segment (Fig. 3A) and also in a greater nerve injury score per segment (Fig. 3B) using the EnligHTN multi-point catheter.

\section{B \\ Mean Nerve Injury Score per Segment}

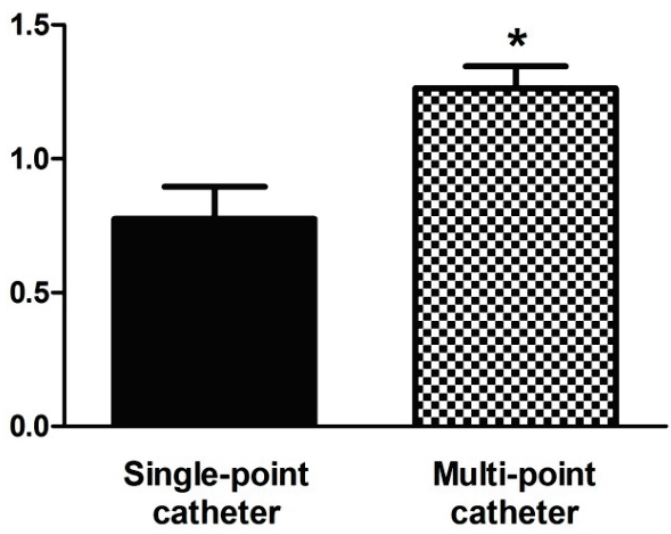

Fig. 3. Comparison of the single-point and multiple-ablation type of catheter to induced vascular and nerve injury found after 10 days post-RDN intervention. A) The mean injury to the renal artery treated with the Symplicity Flex catheter or EnligHTN catheter. B) The mean injury to the renal nerve treated with the Symplicity Flex catheter or EnligHTN catheter. Data are displayed as the mean \pm SEM. The significant differences of the unpaired $T$ tests are presented $\left({ }^{*} \mathrm{p}<0.05\right)$.

Importantly, there were no alterations in the kidney morphology on the intervened side (Fig. 4). No signs of ischemia, hemorrhage, necrosis, or increased leukocyte infiltration were found in the renal cortex (Figs 4A and 4E) or medulla (Figs 4B and 4F) of any kidney sample under study. Both neurofilament proteinpositive (Figs 4C and 4G) as well as tyrosine hydroxylasepositive nerve fibres (Figs 4D and $4 \mathrm{H}$ ) were found in samples of all tissue blocks from all kidneys under study. There was no difference between individual study groups. 

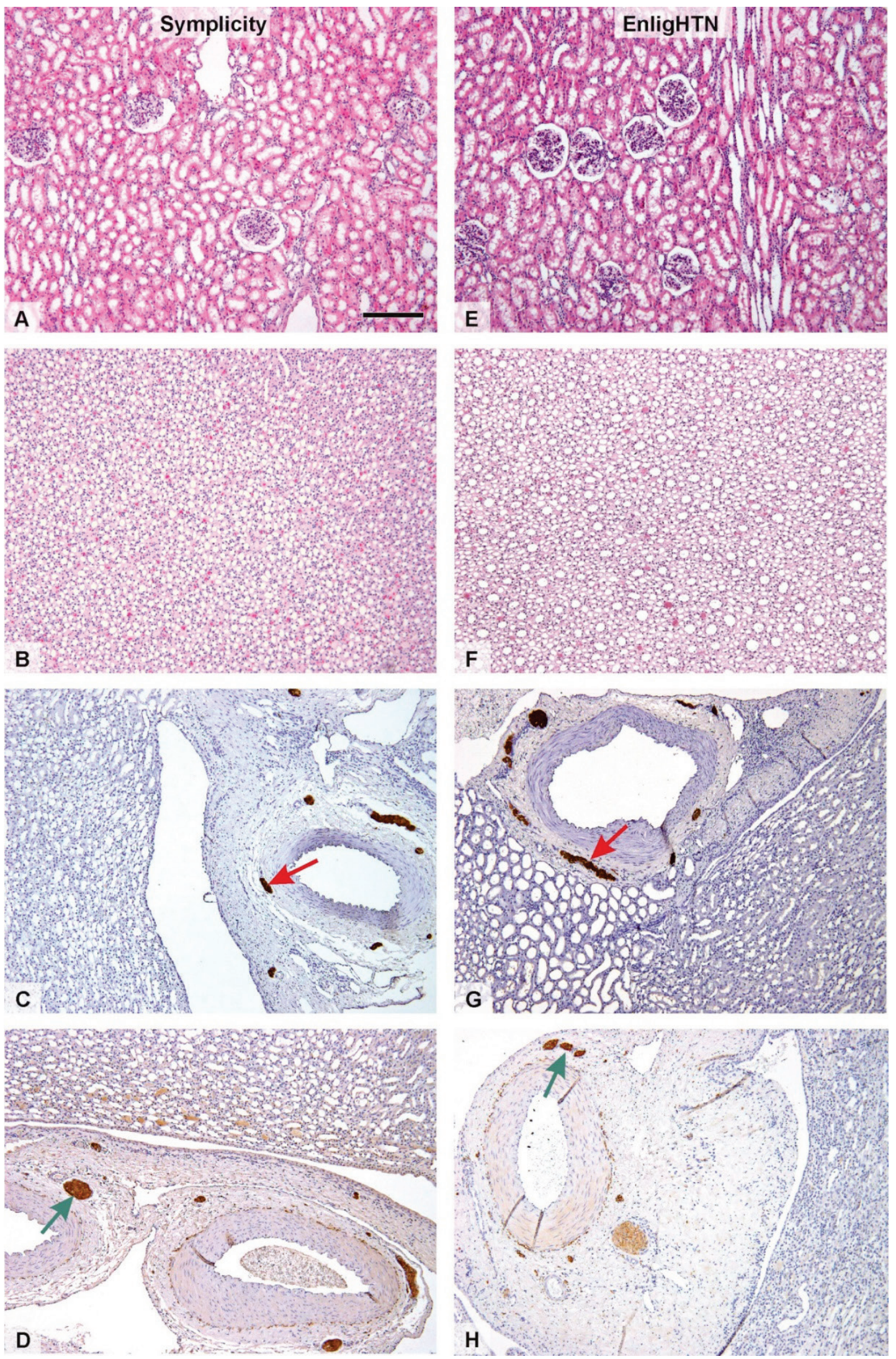

Fig. 4. Representative histological findings illustrating normal microscopic structure of kidneys after 10 days post-RDN intervention using the Symplicity Flex catheter (left) and EnligHTN catheter (right). Renal cortex (A, E) and medulla (B, F) showed no damage, necrosis, or inflammatory infiltration. In both groups of animals, nerves positive for immunohistochemical detection of neurofilament protein (C, G; red arrows) and tyrosine hydroxylase (D, H; green arrows) were found. Hematoxylin-eosin (A, B, E, F), immunohistochemical detection of neurofilament protein (C, G; dark brown positivity), immunohistochemical detection of tyrosine hydroxylase (G-H; dark brown positivity). Scale bar $200 \mu \mathrm{m}(\mathrm{A}-\mathrm{H})$. 


\section{Discussion}

The main goal of this present study was to extend our previous observation (Táborský et al. 2017) whether any further post-RDN processes can lead to the later morphologic alterations in renal artery wall and accompanying renal nerves induced by a single-point and multiple-point ablation catheters in sheep due to a local disruption of the nerves integrity and possible initiation of the reparation processes in the ablation spots. First of all, we confirmed by angiography that there was no noticeable renal artery stenosis or occlusion in the case of RDN-intervened side after a 10-day period. Furthermore, histological evaluation of the kidney tissue morphology revealed no structural alterations and the functional intactness of the kidneys after both RDN procedures were confirmed by unaltered plasma creatinine and urea. Thus, the present study indicates a convenient procedure safety of both methods used in the sheep model.

Histopathological specification and immunohistochemical evaluation of the subacute intravascular, vascular and peri-vascular changes, induced by two types of radio-frequency ablation systems, quantify the degree of the renal artery and renal nerves injury compared to the intact contralateral side. As previously confirmed by our previous study (Táborský et al. 2017), the multi-point ablation catheter led to a significantly higher occurrence of the vascular and perivascular damage. This study also confirmed that both RDN systems used achieved just partial damage of the targeted renal nervous plexus within a 10-day period, most likely due to anatomical specificity of the renal artery wall and the peri-arterial renal nerves distribution in sheep as we reported previously (Táborský et al. 2017). But most importantly, this study showed that any appreciable progression of renal nerve disruption from proximal segments, with evident focal damage to distal parts, was not observed. We did not evaluate the neurofilament quantity or size that might be reduced (Steigerwald et al. 2012) because this assessment did not detect actual and also expectant functional properties of targeted nerves.

In comparison with our previous observation of RDN-induced early changes (Táborský et al. 2017), the status of affected renal arteries provided some initial signs of healing and regeneration similar to study by Steigerwald and colleagues (2012) after a 10-day recovery in pigs. In sheep, a mild thickening of neointima can also be seen without marked presence of inflammatory cell infiltration. This undistinguished inflammatory reaction in sheep may limit further progression of nerve disintegration as minimal damage in distal segments was observed and therefore, these facts may obviously affect the efficiency of RDN procedure to target renal innervation in this study.

The use of multi-point ablation catheters implies that the number of ablation sites increases the probability of induced damage to renal nerves (Tsioufis et al. 2015, Mahfoud et al. 2017, Worthley et al. 2017). However, the efficiency of the multi-point ablation catheters was significantly higher comparted to the single-point system despite the equal number of successful ablations in the present study. Therefore, it seems that simultaneous ablation procedure of multiple spots remains more effective (Mahfoud et al. 2017) and the progressive development of next-generation multi-point ablation catheters and new clinical trials are expected (Kandzari et al. 2016, Townsend et al. 2017, Schlaich and Esler 2017, Worthley et al. 2017). Other technologies such as an ultrasonic ablation catheter may provide new insight into this procedure (Bunte et al. 2013, Chernin et al. 2017). However, more solid data and analysis will be required for renal denervation to become seriously considered as a therapeutic option for patient with resistant hypertension.

We are aware of some study limitations such as a healthy animal model with specific anatomical differences in the thickness of tunica media of the renal artery and also distribution of renal nerve plexus, spatial distribution of their branching and anastomoses, and distance from the renal artery in sheep. These facts may not allow achieving complete or major disruption of the sympathetic nerve plexus accompanying the renal artery. Regenerative processes might be also different in sheep compared to other species and humans. Another limitation was using a semiquantitative scoring system. Further studies mapping the arterial and nerve injury might benefit from stereological quantification of vascular wall using continuous variables (Kochová et al. 2012). Finally, the short follow up of this study did not define any chronic consequences of RDN in sheep model.

In conclusion, although the multipoint ablation system induced significantly pronounced alterations in renal artery wall and accompanying renal nerves, both systems tested in the present study provided only incomplete renal ablation in sheep. There is also no appreciable progression of the nerve disintegration in the subacute phase post-RDN procedure. This study further supports the notion that the effectiveness remains fully 
dependent on anatomical interindividual variability of renal nerves. Therefore, a new system that provides deeper penetrance to targeted perivascular structure would be more efficient.

\section{Conflict of Interest}

There is no conflict of interest.

\section{Acknowledgement}

This work was supported by Ministry of Health of the Czech Republic grant 15-34123A awarded to M.T. and A.H. We would like to acknowledge the technical help of Zuzana Simunkova, Iveta Mrazova, Lenka Cervenkova, Zdenka Vanourkova and Sona Kikerlova.

\section{References}

BAKRIS GL, TOWNSEND RR, FLACK JM, BRAR S, COHEN SA, D'AGOSTINO R, KANDZARI DE, KATZEN BT, LEON MB, MAURI L, NEGOITA M, O’NEILL WW, OPARIL S, ROCHA-SINGH K, BHATT DL; SYMPLICITY HTN-3 INVESTIGATORS: 12-month blood pressure results of catheter-based renal artery denervation for resistant hypertension: the SYMPLICITY HTN-3 trial. J Am Coll Cardiol 65: 1314-1321, 2015.

BHATT DL, KANDZARI DE, O’NEILL WW, D’AGOSTINO R, FLACK JM, KATZEN BT, LEON MB, LIU M, MAURI L, NEGOITA M, COHEN SA, OPARIL S, ROCHA-SINGH K, TOWNSEND RR, BAKRIS GL; SYMPLICITY HTN-3 INVESTIGATORS: A controlled trial of renal denervation for resistant hypertension. N Engl J Med 370: 1393-1401, 2014.

BUNTE MC, INFANTE DE OLIVEIRA E, SHISHEHBOR MH: Endovascular treatment of resistant and uncontrolled hypertension: therapies on the horizon. JACC Cardiovasc Interv 6: 1-9, 2013.

CHERNIN G, SZWARCFITER I, BAUSBACK Y, JONAS M: Renal sympathetic denervation system via intraluminal ultrasonic ablation: therapeutic intravascular ultrasound design and preclinical evaluation. $J$ Vasc Interv Radiol 28: 740-748, 2017.

COHEN-MAZOR M, MATHUR P, STANLEY JR, MENDELSOHN FO, LEE H, BAIRD R, ZANI BG, MARKHAM PM, ROCHA-SINGH K: Evaluation of renal nerve morphological changes and norepinephrine levels following treatment with novel bipolar radiofrequency delivery systems in a porcine model. J Hypertens $\mathbf{3 2}$ : 1678-1691, 2014.

KANDZARI DE, KARIO K, MAHFOUD F, COHEN SA, PILCHER G, POCOCK S, TOWNSEND R, WEBER MA, BÖHM M: The SPYRAL HTN Global Clinical Trial Program: Rationale and design for studies of renal denervation in the absence (SPYRAL HTN OFF-MED) and presence (SPYRAL HTN ON-MED) of antihypertensive medications. Am Heart J 171: 82-91, 2016.

KOCHOVÁ P, KUNCOVÁ J, SVÍGLEROVÁ J, CIMRMAN R, MIKLÍKOVÁ M, LIŠKA V, TONAR Z: The contribution of vascular smooth muscle, elastin and collagen on the passive mechanics of porcine carotid arteries. Physiol Meas 33: 1335-1351, 2012.

MAHFOUD F, LÜSCHER TF, ANDERSSON B, BAUMGARTNER I, CIFKOVA R, DIMARIO C, DOEVENDANS P, FAGARD R, FAJADET J, KOMAJDA M, LEFÈVRE T, LOTAN C, SIEVERT H, VOLPE M, WIDIMSKY P, WIJNS W, WILLIAMS B, WINDECKER S, WITKOWSKI A, ZELLER T, BÖHM M; EUROPEAN SOCIETY OF CARDIOLOGY: Expert consensus document from the European Society of Cardiology on catheter-based renal denervation. Eur Heart J 34: 2149-2157, 2013.

MAHFOUD F, PIPENHAGEN CA, BOYCE MOON L, EWEN S, KULENTHIRAN S, FISH JM, JENSEN JA, VIRMANI R, JONER M, YAHAGI K, TSIOUFIS C, BÖHM M: Comparison of branch and distally focused main renal artery denervation using two different radio-frequency systems in a porcine model. Int $J$ Cardiol 241: 373-378, 2017.

RIPPY MK, ZARINS D, BARMAN NC, WU A, DUNCAN KL, ZARINS CK: Catheter-based renal sympathetic denervation: chronic preclinical evidence for renal artery safety. Clin Res Cardiol 100: 1095-1101, 2011.

SAKAKURA K, TUNEV S, YAHAGI K, O’BRIEN AJ, LADICH E, KOLODGIE FD, MELDER RJ, JONER M, VIRMANI R: Comparison of histopathologic analysis following renal sympathetic denervation over multiple time points. Circ Cardiovasc Interv 8: e01813, 2015. 
SCHLAICH MP, ESLER MD: Renal denervation after the SPYRAL HTN-OFF MED trial: putting a complex study into context. Hypertension 70: 1076-1079, 2017.

STEIGERWALD K, TITOVA A, MALLE C, KENNERKNECHT E, JILEK C, HAUSLEITER J, NÄHRIG JM, LAUGWITZ KL, JONER M: Morphological assessment of renal arteries after radiofrequency catheter-based sympathetic denervation in a porcine model. $J$ Hypertens 30: 2230-2239, 2012.

TÁBORSKÝ M, RICHTER D, TONAR Z, KUBÍKOVÁ T, HERMAN A, PEREGRIN J, ČERVENKOVÁ L, HUSKOVÁ Z, KOPKAN L: Early morphologic alterations in renal artery wall and renal nerves in response to catheter-based renal denervation procedure in sheep: difference between single-point and multiple-point ablation catheters. Physiol Res 66: 601-614, 2017.

TOWNSEND RR, MAHFOUD F, KANDZARI DE, KARIO K, POCOCK S, WEBER MA, EWEN S, TSIOUFIS K, TOUSOULIS D, SHARP ASP, WATKINSON AF, SCHMIEDER RE, SCHMID A, CHOI JW, EAST C, WALTON A, HOPPER I, COHEN DL, WILENSKY R, LEE DP, MA A, DEVIREDDY CM, LEA JP, LURZ PC, FENGLER K, DAVIES J, CHAPMAN N, COHEN SA, DEBRUIN V, FAHY M, JONES DE, ROTHMAN M, BÖHM M; SPYRAL HTN-OFF MED TRIAL INVESTIGATORS: Catheter-based renal denervation in patients with uncontrolled hypertension in the absence of antihypertensive medications (SPYRAL HTN-OFF MED): a randomised, sham-controlled, proof-of-concept trial. Lancet 390: 2160-2170, 2017.

TSIOUFIS CP, PAPADEMETRIOU V, DIMITRIADIS KS, KASIAKOGIAS A, TSIACHRIS D, WORTHLEY MI, SINHAL AR, CHEW DP, MEREDITH IT, MALAIAPAN Y, THOMOPOULOS C, KALLIKAZAROS I, TOUSOULIS D, WORTHLEY SG: Catheter-based renal denervation for resistant hypertension: twenty-four month results of the EnligHTN I first-in-human study using a multi-electrode ablation system. Int $J$ Cardiol 201: 345-350, 2015.

WORTHLEY SG, WILKINS GT, WEBSTER MW, MONTARELLO JK, DELACROIX S, WHITBOURN RJ, WARREN RJ: Safety and performance of the second generation EnligHTNTM Renal Denervation System in patients with drug-resistant, uncontrolled hypertension. Atherosclerosis 262: 94-100, 2017. 